Website: http://revistas.lamolina.edu.pe/index.php/acu/index

(C) Universidad Nacional Agraria La Molina, Lima - Perú

\title{
Uso de inductores de defensa en la prevención de infecciones ocasionadas por Lasiodiplodia theobromae, en plantones de vid (Vitis vinifera) en Perú
}

\author{
Use of defense inductors in the prevention of infections caused by Lasiodiplodia theobromae, in vine plant
}

(Vitis vinifera) in Peru

\author{
Jose Miguel Soto Heredia ${ }^{1 *} \&$ Carlos Alberto Cadenas Giraldo ${ }^{2}$ \\ *Autor de correspondencia
}

\section{Resumen}

El objetivo del presente trabajo de investigación fue evaluar el efecto de seis sustancias químicas (Ácido fosforoso, fosetil aluminio, fosfito de potasio, sulfato de cobre pentahidratado, mananos oligosacáridos, acibenzolar-S-metil) y dos agentes biológicos (Bacillus subtilis y Trichoderma harzianum), en la prevención de Lasiodiplodia theobromae, utilizados como inductores de defensas en plantas de vid "Red Globe" injertados sobre patrón Harmony. Los tratamientos fueron aplicados de manera preventiva, se realizaron tres aplicaciones foliares de los productos con intervalos de diez días entre aplicación, posteriormente 5 días después de la última aplicación fueron inoculadas con micelio de L. theobromae, tanto en la variedad como en el patrón mediante una herida. Las evaluaciones se realizaron a los 40 días después de la inoculación y se consideró tanto la incidencia y el área de las lesiones necróticas presentes. Para la incidencia se calculó el número de plantas con lesiones necróticas y para el área de infección se utilizó el programa de análisis de imagen ASSESS 9.1 para determinar el área de la lesión $\left(\mathrm{cm}^{2}\right)$. Para el análisis estadístico se utilizó un diseño completamente al azar (DCA), una comparación de media Tukey con un nivel de significancia del $95 \%(\alpha=0,05)$. Los mejores resultados se obtuvieron con los tratamientos con menores porcentajes de incidencia: Mananos oligosacáridos, acibenzolar-S-metil y fosetil de aluminio, los cuales mostraron se eficaces en la prevención de la enfermedad ocasionada por L. theobromae.

Palabras clave: Acibenzolar-S-metil; Red Globe; muerte regresiva; inductores de defensa; mananos oligosacaridos.

\begin{abstract}
The objective of this research work was to evaluate the effect of six chemical substances (phosphorous acid, aluminum fosetyl, potassium phosphite, copper sulfate pentahydrate, mannans oligosaccharides, acibenzolar-S-metil) and two biological agents (Bacillus subtilis and Trichoderma harzianum), in the prevention of Lasiodiplodia theobromae, used as defense inducers in grape plants "Red Globe" grafted onto 'Harmony' rootstock were used. The treatments were applied in a preventive way, three foliar applications of the products were made with intervals of ten days between application, later 5 days after the last application they were inoculated with $L$ theobromae mycelium, both in the variety and in the pattern by means of a wound. The evaluations were made 40 days after the inoculation and both the incidence and the area of the necrotic lesions present were considered. For the incidence, the number of plants with necrotic lesions was calculated and for the area of infection the ASSESS 9.1 image analysis program was used to determine the area of the lesion $\left(\mathrm{cm}^{2}\right)$. For the statistical analysis we used a completely randomized design (DCA) a Tukey mean comparison with a level of significance of $95 \%(\alpha=0.05)$. The best results were obtained with the treatments with lower percentages of incidence: oligosaccharide mannans, acibenzolar-S-methyl and aluminum fosetil, which were effective in the prevention of the disease caused by $L$. theobromae.
\end{abstract}

Keywords: Acibenzolar-S-methyl; Red Globe; dieback; inductors of defense; mannans oligosaccharides.

\section{Introducción}

El cultivo de la vid (Vitis vinifera L.) es extensamente cultivado en el mundo, en un área de 10 millones de hectáreas aproximadamente. La vid se desarrolla tanto en regiones templadas como tropicales, pero la mayoría de viñedos se establecen en zonas de climas templados, concentrándose la mayor cantidad en Europa. Constituye además una de las actividades frutícolas de mayor importancia en el Perú por su extensión, por su valor de producción y por ser fuente de la materia prima que requiere la industria vitivinícola nacional (Pearson, 2011). En la actualidad, hay cerca de 29,777 hectáreas cultivadas con uva de mesa para la exportación en la costa peruana, desde Moquegua hasta Piura. Ica es la principal región productora con el $40,7 \%$ del volumen nacional exportado, seguido de Piura con el 23,7 \% y Lima con 13,3\% (MINAGRI, 2017). La vid es afectada por diversas enfermedades que merman la producción tales como la muerte regresiva (Lasiodiplodia

\footnotetext{
${ }^{1}$ Departamento Académico de Fitopatología, Facultad de Agronomía, Universidad Nacional Agraria La molina, Apartado postal 12-056- La Molina, Lima, Perú. Email: Jomish28@hotmail.com

${ }^{2}$ Departamento Académico de Fitopatología, Facultad de Agronomía, Universidad Nacional Agraria La molina, Apartado postal 12-056- La Molina, Lima, Perú. Email: ccadenas@lamolina.edu.
} 
theobromae), la enfermedad de Petri (Phaeoacremonium spp. y Phaeomoniella chlamydospora), la Eutipiosis (Eutypa lata), la Yesca (Fomitiporia mediterranea), entre otros (Reynier, 1989).

L. theobromae (Pat.) Griffon and Maubl es la especie tipo género Lasiodiplodia, el cual es un hongo que fue descrito por primera vez hacia 1890 por Saccardo, afectando frutos de cacao (Theobromae cacao) en ecuador (Crous y Palm, 1999). Este hongo es cosmopolita y tiene una gama de hospederos, incluidos monocotiledóneas, dicotiledóneas y gimnospermas, especialmente de los trópicos y subtrópicos. Es un hongo pleomórfico y ubicuo, por lo cual ha tenido más de un sinónimo (Abdollahzadeh et al., 2010).

La muerte regresiva de la vid, causada por Lasiodiplodia theobromae, ocasiona una reducción del crecimiento y un decaimiento general de las plantas. Esta enfermedad afecta principalmente a las plantas jóvenes causando enormes pérdidas en nuevas plantaciones. En campos instalados con vid es difícil curar las plantas infectadas con $L$. theobromae debido a que este hongo se localiza en los tallos, tanto a nivel de patrón como en el injerto, siendo la principal fuente de inóculo el material de propagación infectado, por tal motivo, durante el proceso de propagación de la vid en vivero y en campo, se debe tomar medidas que eviten la contaminación del material. (Mugnai et al., 1999; Poscoe \& Cotral, 2000).

Los antecedentes del potencial de ciertos productos químicos y biológicos en la prevención de diversas enfermedades, como aplicaciones exógenas de Ácido salicílico (SA) y compuestos sintéticos como acibenzolarS-metil (ASM) han mostrado activar la resistencia sistémica adquirida y ser efectivo contra una amplia gama de patógenos y vinculado a la producción de proteínas relacionadas a la patogénesis (PR). El SIR es inducido comúnmente por Rizobacterias y en contraste con el SAR la señalización esta mediada por el jasmonato y etileno (Van Loon \& Pieterse, 2006). Compuestos como mananos oligosacaridos (PMO) en lo cual el principal activo es extraído de la pared de Saccharomyces cerevisiae puede activar también la resistencia en plantas (Costa et al., 2010). Otros compuestos sintéticos como fosetil aluminio han reportado una doble acción con un efecto directo fungitóxico y un efecto indirecto involucrando la activación de defensa sistémica en plantas. Solo existe evidencia clara que los derivados de este compuesto pueden involucrar en la formación de fitoalexinas y compuestos fenólicos (Guest, 1984). Por ello, en esta investigación tuvo como objetivo general determinar la eficacia en vivero de seis productos inductores de defensa de naturaleza química: Ácido fosforoso, fosetil de aluminio, fosfito de potasio, sulfato de cobre pentahidratado, mananos oligosacáridos, acibenzolar S-metil, y dos de naturaleza biológica: Bacillus subtilis, Trichoderma harzianum; utilizados como inductores de defensa para prevenir la muerte regresiva causada por $L$. theobromae en plantones de vid en vivero.

\section{Materiales y métodos}

El presente trabajo de investigación se realizó en el vivero de la empresa Los Viñedos ubicado en el Kilómetro 201 de la Panamericana Sur, perteneciente al Fundo El Retiro Lote 75, Distrito de Chincha Baja, Provincia de Chincha y Departamento de Ica.

Para la obtención del inóculo, se seleccionaron plantas madres de vid de la variedad Red Globe con síntomas de muerte regresiva característicos de las infecciones con $L$. theobromae. Los brotes de las plantas seleccionadas se cortaron con una tijera de podar y fueron colocadas en una bolsa de polipropileno y llevados al laboratorio para realizar el aislamiento del patógeno. En el laboratorio del vivero se seleccionaron las partes necróticas de las ramas o brotes con su zona de avance asintomático, se procedieron a lavarlas con agua potable y se cortaron en porciones pequeñas de aproximadamente $5 \mathrm{~mm}$ de diámetro abarcando la zona de avance de la enfermedad, posteriormente se procedió a colocarlas en una solución de alcohol al $96 \%$ por 5 minutos con el propósito de eliminar los contaminantes y microorganismos superficiales y luego se dejaron secar sobre papel toalla estéril.

Las porciones de tejido, desinfestadas y secas, se sembraron en placas Petri conteniendo medio de cultivo Extracto de Malta Agar (MEA) de la marca Merck disponiendo 5 porciones en forma de cruz. Las placas sembradas se colocaron por cuatro días en la incubadora a una temperatura de $25{ }^{\circ} \mathrm{C}$ para permitir el crecimiento del hongo (Santiago et al., 2015). Transcurrido el tiempo se hicieron observaciones al microscopio estereoscopio para determinar la presencia de las esporulaciones del hongo. Se hicieron preparaciones microscópicas de las estructuras fructificantes formadas en las colonias en láminas porta y cubreobjetos las cuales fueron observadas al microscopio compuesto para la identificación correspondiente. Se utilizó las claves de Barnett \& Hunter (1996) para corroborar el género taxonómico; y la clave de Sutton (1980) y el descriptor de la Commonwealth Mycological Institute (CMI) para la corroboración a nivel específico El hongo identificado se inoculó en plantones de vid para determinar la patogenicidad de L. theobromae aislado de plantas con síntomas característico de la enfermedad, en la cual se utilizó el mismo material vegetal y metodología empleado en los tratamientos.

Para la fase de vivero se utilizaron estacas enraizadas de vid sanos de la variedad Red Globe injertadas sobre patrón Harmony con una edad de cinco meses y una altura promedio de $50 \mathrm{~cm}$, que previamente fueron pasadas por un proceso de termoterapia a temperatura de $53{ }^{\circ} \mathrm{C}$ por un tiempo de 30 minutos. Se instalaron en diez bandejas con sustrato estéril compuesta por una mezcla de coco, humus y pajilla de arroz en las proporciones (1-1-1/2), regadas por sistema de goteo. Los productos que se utilizaron en los tratamientos en el presente trabajo de investigación fueron ocho en total, seis de naturaleza química y dos de naturaleza biológica, incluyendo testigo sin inocular y testigo inoculado, los cuales se presentan en la Tabla 1. 
Tabla 1. Tratamientos de productos químicos y biológicos contra $L$. theobromae, en fase de vivero

\begin{tabular}{|c|c|c|c|}
\hline Tratamiento & $\begin{array}{l}\text { Ingrediente } \\
\text { activo }\end{array}$ & Dosis & Aplicación \\
\hline 1 & $\begin{array}{l}\text { Acido } \\
\text { fosforoso }\end{array}$ & $1,0 \mathrm{~L} / 200 \mathrm{~L}$ de agua & Drench \\
\hline 2 & $\begin{array}{l}\text { Fosetil de } \\
\text { Aluminio }\end{array}$ & $0,5 \mathrm{~kg} / 200 \mathrm{~L}$ de agua & Foliar \\
\hline 3 & $\begin{array}{l}\text { Fosfito de } \\
\text { potasio }\end{array}$ & $0,5 \mathrm{~L} / 200 \mathrm{~L}$ de agua & Foliar \\
\hline 4 & $\begin{array}{c}\text { Sulfato } \\
\text { de cobre } \\
\text { pentahidratado }\end{array}$ & $0,4 \mathrm{~L} / 200 \mathrm{~L}$ de agua & Foliar \\
\hline 5 & $\begin{array}{c}\text { Mananos } \\
\text { oligosacáridos }\end{array}$ & $0,5 \mathrm{~L} / 200 \mathrm{~L}$ de agua & Foliar \\
\hline 6 & $\begin{array}{l}\text { Acibenzolar } \\
\text { S-methyl }\end{array}$ & $10,0 \mathrm{~g} / 200 \mathrm{~L}$ de agua & Foliar \\
\hline 7 & $\begin{array}{l}\text { Trichoderma } \\
\text { harzianum }\end{array}$ & $5 \mathrm{~g} / \mathrm{L}$ de agua & Foliar \\
\hline 8 & $\begin{array}{l}\text { Bacillus subti- } \\
\quad \text { lis }(0,2 \%)\end{array}$ & $5 \mathrm{~g} / \mathrm{L}$ de agua & Foliar \\
\hline 9 & $\begin{array}{l}\text { Testigo sin } \\
\text { inocular }\end{array}$ & Agua sola & Foliar \\
\hline 10 & $\begin{array}{l}\text { Testigo } \\
\text { inoculado }\end{array}$ & Agua sola & \\
\hline
\end{tabular}

Las aplicaciones de los productos químicos y biológicos de los tratamientos se iniciaron 2 meses después de la injertación considerando como el día cero. Estas fueron realizadas en tres oportunidades en intervalos de diez días entre aplicaciones cinco días después de la última aplicación se inocularon las plantas de cada tratamiento con el hongo L. theobromae, previamente aislado $\mathrm{e}$ identificado. Se utilizó un asperjador de la marca Arsus con capacidad de 2 litros, los ingredientes activos fueron pesados en la cantidad equivalente a la dosis comercial y mezclados con agua en una cantidad de $360 \mathrm{ml}$. por tratamiento con adición de un surfactante siliconado para disminuir la tensión superficial del agua permitiendo un mejor mojamiento, para aplicación en suelo se calculó el gasto de agua para evitar perdida de producto, se realizó un vaciado al sustrato en una cantidad de $400 \mathrm{ml}$. de agua.

En cada plantón de vid se realizaron dos heridas circulares de $5 \mathrm{~mm}$ de diámetro con un sacabocado previamente desinfectado, haciendo una presión leve en el tallo para extraer la porción de corteza, una en la zona del patrón ubicado en una distancia media entre la base y la zona injerto y la otra en la zona del injerto ubicado en una distancia donde el grosor fue $1 \mathrm{~cm}$ aproximado. En el área de tejido expuesto se colocó una rodaja de $5 \mathrm{~mm}$ de medio MEA conteniendo el crecimiento de 4 días de edad de micelio de L. theobromae. Las heridas inoculadas se cubrieron con un trozo pequeño de algodón humedecido con agua destilada estéril para generar humedad al hongo y finalmente se envolvió con cinta de parafilm, esta metodología fue tomada como referencia de los trabajos en vid realizados por Urbez-Torres et al. (2008). Los plantones inoculados se dejaron puestas dentro de un tinglado del vivero hecho de malla Raschel hasta ver la observación de los síntomas secundarios y primarios; así como de la presencia de los signos correspondientes.
Transcurridos 40 días después de la inoculación, se realizaron las evaluaciones de los plantones en todos los tratamientos. Los parámetros que se evaluaron fueron: a. Incidencia, contando el número de plantas que mostraron síntoma visual de pudrición externa en avance en los tallos que fueron ocasionados directamente por el patógeno inoculado; b. Pudrición externa en los tallos, para lo cual se efectuó un raspado de la superficie de los tallos desde los puntos de inoculación hacia sus cuatros lados (superior, inferior, izquierda y derecha) exponiendo el tejido cortical afectado; evaluándose tanto de la zona del patrón como en la del injerto. Se calcó el área afectada colocándole papel celofán ceñido al tallo, posteriormente estos dibujos fueron copiados a un papel blanco y para determinar el área $\left(\mathrm{cm}^{2}\right)$ infectada estos dibujos fueron llevadas al gabinete donde se utilizó el programa de análisis de imagen para la cuantificación de la enfermedad en plantas (ASSESS 9.1); c. Pudrición interna de los tallos, después del raspado superficial de los tallos, se realizaron cortes longitudinales para medir el avance de la necrosis por los haces vasculares, tanto hacia arriba como hacia abajo del punto de inoculación, y para esta evaluación se utilizó una regla milimetrada. d. Porcentaje de inhibición del hongo, la cual se utilizó la fórmula de \% de inhibición $=\{[$ Testigo inoculado - Tratamiento) / Testigo inoculado)] x 100$\}$.

El diseño experimental que se empleó fue el completamente al Azar (DCA), con 10 tratamientos y 12 repeticiones. Para las variables evaluadas se realizaron Análisis de homogeneidad de variancia y normalidad. La Prueba de comparación de medias de Tukey, consideró un nivel de confianza del $95 \%(\alpha=0,05)$, para lo cual se utilizó el Statistical Analisys Software (SAS Institute, 2004), versión 9.1.

\section{Resultados y discusión}

En la prueba de patogenicidad se observó plantones con pérdida de vigor, reducción de las distancias de los entrenudos, hojas cloróticas y el signo la cuales fueron picnidias con la presencia de cirrus, síntomas y signos que corresponde a los reportados en los trabajos realizados por Urbez-Torres et al. (2008).

Los resultados de las evaluaciones de incidencia de la enfermedad muestran que los tratamientos: Testigo inoculado, fosfito de potasio, B. subtilis, ácido fosforoso, y $T$. harzianum, presentaron un $100 \%$ de incidencia de la enfermedad tanto en el patrón como en el injerto.

En el tratamiento con sulfato de cobre pentahidratado se observó una planta sin infección en la zona del injerto, pero si con síntoma de infección en el patrón. En el tratamiento con fosetil aluminio solamente dos plantas no tuvieron síntomas de infección en la zona del injerto, pero si todos en el patrón. Para los tratamientos con mananos oligosacáridos y testigo sin inocular no se observaron síntomas de infecciones, ni en la zona del injerto ni en el patrón, y por último el tratamiento con acibenzolar-Smetil solo se evidenció una planta con infección en la zona patrón (Tabla 2). 
Tabla 2. Incidencia de infección por L. theobromae en plantas de vid inoculadas en el patrón e injerto

\begin{tabular}{|c|c|c|c|c|}
\hline $\mathrm{N}^{\circ}$ & Tratamiento & Descripción & $\begin{array}{c}\mathrm{N}^{\circ} \mathrm{de} \\
\text { Plantas } \\
\text { afectadas }\end{array}$ & $\underset{\%}{\text { Incidencia }}$ \\
\hline \multirow{2}{*}{10} & \multirow{2}{*}{ Testigo inoculado } & Injerto & $12 / 12$ & 100 \\
\hline & & Patrón & $12 / 12$ & 100 \\
\hline \multirow{2}{*}{3} & \multirow{2}{*}{ Fosfito de potasio } & Injerto & $12 / 12$ & 100 \\
\hline & & Patrón & $12 / 12$ & 100 \\
\hline \multirow{2}{*}{8} & \multirow{2}{*}{ Bacillus subtilis } & Injerto & $12 / 12$ & 100 \\
\hline & & Patrón & $12 / 12$ & 100 \\
\hline \multirow{2}{*}{1} & \multirow{2}{*}{ Ac. fosforoso } & Injerto & $12 / 12$ & 100 \\
\hline & & Patrón & $12 / 12$ & 100 \\
\hline \multirow{2}{*}{7} & \multirow{2}{*}{ T. harzianum } & Injerto & $12 / 12$ & 100 \\
\hline & & Patrón & $12 / 12$ & 100 \\
\hline \multirow{2}{*}{4} & \multirow{2}{*}{$\begin{array}{l}\text { Sulfato de cobre } \\
\text { Pent. }\end{array}$} & Injerto & $11 / 12$ & 91,6 \\
\hline & & Patrón & $12 / 12$ & 100 \\
\hline \multirow{2}{*}{2} & \multirow{2}{*}{ Fosetil de aluminio } & Injerto & $10 / 12$ & 83,3 \\
\hline & & Patrón & $12 / 12$ & 100 \\
\hline \multirow{2}{*}{5} & \multirow{2}{*}{$\begin{array}{c}\text { Mananos } \\
\text { oligosacáridos }\end{array}$} & Injerto & $0 / 12$ & 0 \\
\hline & & Patrón & $0 / 12$ & 0 \\
\hline \multirow{2}{*}{6} & \multirow{2}{*}{$\begin{array}{l}\text { Acibenzolar-S- } \\
\text { Methil }\end{array}$} & Injerto & $0 / 12$ & 0 \\
\hline & & Patrón & $1 / 12$ & 8,3 \\
\hline \multirow{2}{*}{9} & \multirow{2}{*}{$\begin{array}{l}\text { Testigo sin } \\
\text { inocular }\end{array}$} & Injerto & $0 / 12$ & 0 \\
\hline & & Patrón & $0 / 12$ & 0 \\
\hline
\end{tabular}

En las evaluaciones de las áreas de los síntomas externos en tallos, las comparaciones de las áreas de las infecciones entre patrón e injerto en cada uno de los diversos tratamientos se presentan en la Figura 1, donde se observa que hay diferencias en el avance entre el injerto y el patrón. El avance en área en el injerto es menor al del patrón en la mayoría de los tratamientos.

En la Figura 2 se observa los síntomas de las pudriciones de tallos que se presentaron en el injerto de los diversos tratamientos; y en la Figura 3 se observan los síntomas de las pudriciones de tallos que se presentaron en el patrón.

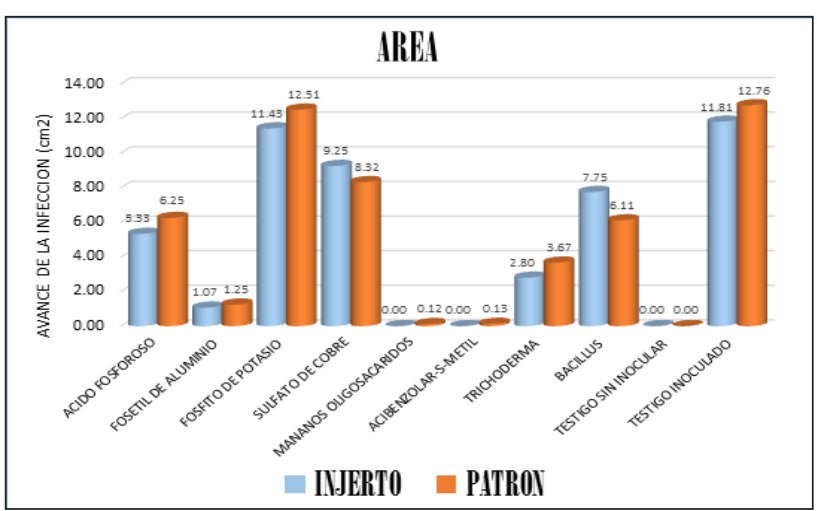

Figura 1. Comparaciones de las áreas de las infecciones por $L$ theobromae entre el injerto y patrón en plantas de vid tratadas con productos químicos y biológicos

Las comparaciones de las distancias longitudinales de las infecciones por L. theobromae, entre patrón e injerto en los diversos tratamientos se presentan en la Figura 4. Se observa que hay diferencias de las longitudes de las lesiones entre el injerto y patrón. El avance longitudinal en el injerto es mayor que el patrón en la mayoría de los tratamientos.

Las infecciones en los tallos en los plantones a partir del punto de inoculación tanto en el en el injerto como en el patrón se pudieron notar que estos son algo mayores hacia la parte de abajo que las de arriba, estas características son similares a los obtenidos en sus trabajos de investigación por Urbez-Torres et al. (2008).

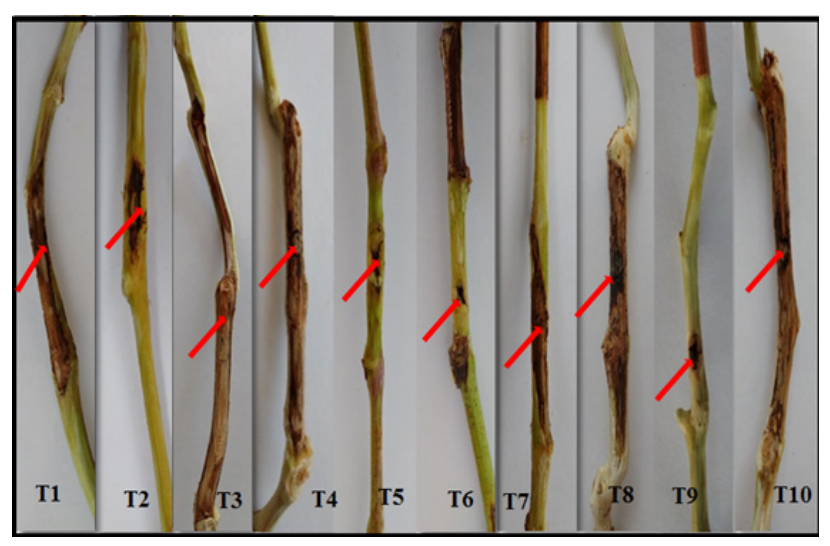

Figura 2. Comparación de injerto de los diferentes tratamientos con raspado cortical. T1 (Ac. fosforoso), T2 (Fosetil de aluminio), T3 (Fosfito de potasio), T4 (Sulfato de cobre pentahidratado), T5 (Mananos oligosacáridos), T6 (Acibenzolar-S-metil), T7 (Trichoderma harzianun), T8 (Bacillus subtilis), T9 (Testigo sin inocular), T10 (Testigo inoculado)

Las distancias (mm) de infección a partir del punto de inoculación fueron en su mayoría superiores en la variedad que en el patrón, estas diferencias podrían deberse a factores como tipo de tejido inoculado, edad del hospedante y/o diferencias en la susceptibilidad de la variedad, entre otros factores que influyan en el avance del patógeno (Van Niekerk et al., 2004), aunque, esta relación es contraria, ya que el patrón a pesar de tener distancias algo menores en comparación a la variedad, en varios tratamientos las áreas $\left(\mathrm{cm}^{2}\right)$ fueron mayores en el patrón.

Los productos a base de fósforo como el caso de ácido fosforoso y fosfito de potasio no mostraron tener ningún efecto positivo en el control de la infección por L. theobromae, aun cuando estas alcanzaron niveles casi igual a las del testigo inoculado; aunque existe reportes con estos productos para otros cultivos con diferente patógeno, donde si mostraron tener cierta eficacia en el control. Su poca eficacia en el control puede ser explicado que no hay fundamentos en que estos productos activen la resistencia de manera sistémica; pero los mecanismos de defensas no son solamente de forma sistémica, siendo también mediante la producción de compuestos microbicidas como las fitoalexinas, de ser así, no necesariamente pueden producirse fitoalexinas en cantidades elevadas como para 
inhibir el avance del patógeno (Agrios, 1996). Esto quizá pudiera ser manejado por la dosis del producto a aplicar, ya que en el presente trabajo de investigación las cantidades de los productos que se aplicaron fueron en relación a la dosis comercial recomendada y no necesariamente a una dosis que pueda funcionar como inductor de defensas en cantidades suficientes.

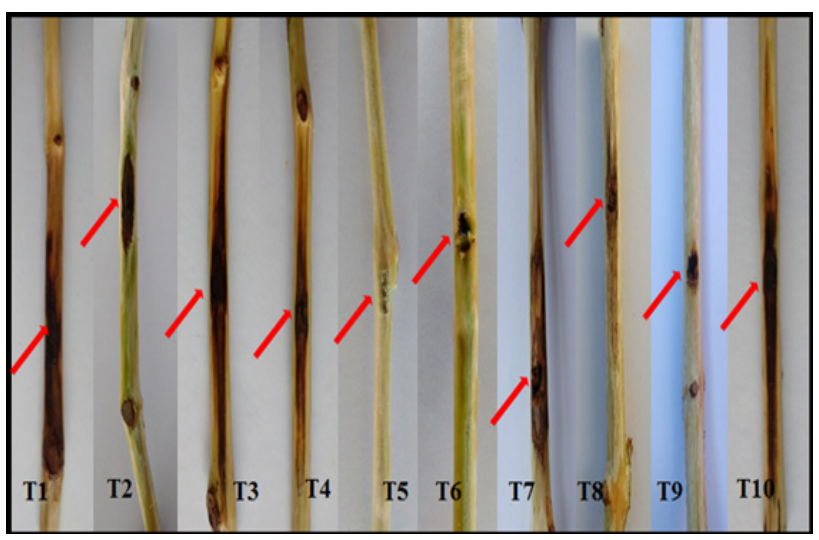

Figura 3. Comparación de patrones de los diferentes tratamientos con raspado cortical . T1 (Ac. fosforoso), T2 (Fosetil de aluminio), T3 (Fosfito de potasio), T4 (Sulfato de cobre pentahidratado), T5 (Mananos oligosacáridos), T6 (Acibenzolar-S-metil), T7 (Trichoderma harzianun), T8 (Bacillus subtilis), T9 (Testigo sin inocular), T10 (Testigo inoculado)

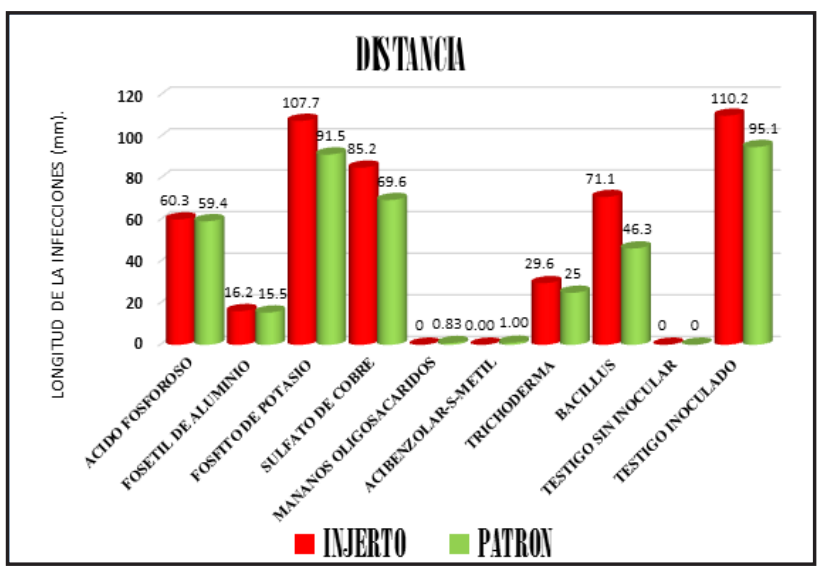

Figura 4. Comparaciones de las longitudes por infecciones por $L$ theobromae entre los injertos y patrones

En este ensayo fosetil de aluminio obtuvo buenos resultados en esta metodología preventiva, con avances de las pudriciones muy bajas, con porcentaje de inhibición mayor al $80 \%$. Hay muchas evidencias en investigaciones que muestran que la aplicación de fosetil de aluminio participa en la producción de fitoalexinas (Guest, 1986).

Los productos manamos oligosacáridos y acibenzolarS-metil mostraron ser los mejores en la prevención de $L$. theobromae controlando en un $100 \%$ la enfermedad en el injerto y cerca al $100 \%$ en el patrón. Estos resultados son similares a los obtenidos en estudios previos con dichos productos, donde se muestran su poder activador de defensa en plantas, donde se usaron ácido salicílico aplicados exógenamente para Botrytis cinerea (Renault et al., 1996) y aplicaciones de mananos oligosacáridos contra Plasmopara vitícola en vid, donde mostraron tener buena eficacia como activadores de defensa contra patógenos en plantas (Kedma et al., 2012).

En los tratamientos con mananos oligosacáridos y con acibenzolar-s-metil se produjo un bloqueo en el avance del patógeno por la formación de una cicatriz en forma de "labio", lo que podría indicar la acumulación de sustancias de refuerzos como enzimas ricas en hidroxiprolina y la formación de suberina (Ryals et al., 1996).

Entre los procesos de defensa de la planta se incluyen la muerte programada de las células, y no solo existe una muerte como tal, sino que se forman y acumulan otros compuestos que son tóxicos para el patógeno y las células hospedantes (Heath, 2000). La activación de estos mecanismos puede variar dependiendo el cultivar e inclusive la especie, donde el tiempo de activación pueden ser variables (Schneider et al., 1996).

Los resultados de análisis de variancia de las lesiones de las áreas en los injertos indican que existen diferencias altamente significativas entre los tratamientos. La prueba de comparación de media de Tukey de las áreas de avance en los injertos de los tratamientos se presentan en la Tabla 3 , indica que los mejores resultados se obtuvieron con los tratamientos mananos oligosacáridos y acibenzolar- Smetil, debido a la menor severidad en el área de avance de $L$. theobromae y que fueron estadísticamente iguales a lo obtenido en el testigo sin inocular, lo cual representa un $100 \%$ de control de la enfermedad para estos tratamientos.

Tabla 3. Resultados del análisis de área de las infecciones por L. theobromae en el patrón de plantas de vid con distintos tratamientos en la prevención de la enfermedad

\begin{tabular}{lccc}
\hline \multicolumn{1}{c}{ Tratamientos } & $\begin{array}{c}\text { Media del } \\
\text { área de } \\
\text { infección } \\
\text { real }\end{array}$ & $\begin{array}{c}\text { Media } \\
\text { transformada } \\
\text { de área de } \\
\text { infección }\end{array}$ & \\
& $11,81^{\mathrm{x}}$ & $4,43^{\mathrm{y}}$ & $\mathrm{A}^{\mathrm{z}}$ \\
\hline 10: Testigo inoculado & 11,42 & 4,37 & $\mathrm{~A}$ \\
3: Fosfito de potasio & 9,25 & 4,03 & $\mathrm{~B}$ \\
4: Sulfato de cobre & 7,75 & 3,78 & $\mathrm{C}$ \\
pentahidratado & 5,33 & 3,29 & $\mathrm{D}$ \\
8: Bacillus subtilis & 2,80 & 2,66 & $\mathrm{E}$ \\
1: Ácido fosforoso & 1,06 & 1,98 & $\mathrm{~F}$ \\
7: Trichoderma harzianum & G & $\mathrm{G}$ \\
2: Fosetil de aluminio & 0,00 & 1,00 & $\mathrm{G}$ \\
5: Mananos oligosacáridos & 0,00 & 1,00 & $\mathrm{G}$ \\
6: Acibenzolar-S-Methyl & 0,00 & 1,00 & \\
9: Testigo sin inocular & & $2,47 \%$ & \\
Coeficiente de variabilidad & & & \\
\hline
\end{tabular}

$\mathrm{X}$ valor real de tratamiento. ${ }^{\mathrm{Y}}$ Datos convertidos a $(\sqrt{ } \%+1) .{ }^{\mathrm{Z}}$ Números en columnas seguidos por la misma letra no son significativamente diferentes de acuerdo a la prueba de Tukey.

El tratamiento fosetil aluminio, tuvo un de área de avance de infección de $1,06 \mathrm{~cm}^{2}$, pero fue estadísticamente 
diferente a los tratamientos anteriormente mencionados y representó un $92,3 \%$ de control con respecto al testigo inoculado. Por lo que se considera que estos tratamientos (mananos oligosacáridos y acibenzolar- S- metil y fosetil de aluminio) mostraron tener un buen efecto inductor de defensa contra L. theobromae.

Los tratamientos Trichoderma harzianum, ácido fosforoso, Bacillus subtilis, sulfato de cobre pentahidratado tuvieron un área de avance media de 2,80, 5,33, 7,75 y $9,25 \mathrm{~cm}^{2}$ respectivamente, siendo todos estos tratamientos estadísticamente diferentes entre sí y entre los otros. Estos tratamientos tuvieron un efecto poco importante en la prevención del avance de la enfermedad, representando un porcentaje de control menor a $35 \%$ en el mejor de los casos.

Tabla 4. Resultados del análisis de área de las infecciones por $L$. theobromae en el patrón de plantas de vid con distintos tratamientos en la prevención de la enfermedad

\begin{tabular}{|c|c|c|c|}
\hline Tratamientos & $\begin{array}{l}\text { Media del } \\
\text { área de } \\
\text { infección } \\
\text { real }\end{array}$ & $\begin{array}{c}\text { Media } \\
\text { transformada } \\
\text { de área de } \\
\text { infección }\end{array}$ & Agrupamiento \\
\hline 10: Testigo inoculado & $12,76^{\mathrm{X}}$ & $4,57^{Y}$ & $\mathrm{~A}^{\mathrm{z}}$ \\
\hline 3: Fosfito de potasio & 12,50 & 4,53 & A \\
\hline $\begin{array}{l}\text { 4: Sulfato de cobre } \\
\text { pentahidratado }\end{array}$ & 8,32 & 3,80 & B \\
\hline 1: Ácido fosforoso & 6,25 & 3,49 & B \\
\hline 8: Bacillus subtilis & 6,11 & 3,46 & B \\
\hline 7: Trichoderma harzianum & 3,66 & 2,91 & $\mathrm{C}$ \\
\hline 2: Fosetil de aluminio & 1,24 & 2,11 & $\mathrm{D}$ \\
\hline 6: Acibenzolar-S-metil & 0,13 & 1,15 & $\mathrm{E}$ \\
\hline 5: Mananos oligosacáridos & 0,11 & 1,09 & $\mathrm{E}$ \\
\hline 9: Testigo sin inocular & 0,00 & 1,00 & $\mathrm{E}$ \\
\hline Coeficiente de variabilidad & \multicolumn{2}{|c|}{$5,07 \%$} & \\
\hline
\end{tabular}

Los tratamientos fosfito de potasio y testigo inoculado tuvieron un área de avance media de 11,42 y 11,81 $\mathrm{cm}^{2}$ respectivamente, no existiendo diferencias estadísticas entre estos tratamientos lo que indica que el fosfito de potasio no tuvo ningún efecto de control.

Los resultados de análisis de variancia de las áreas de las lesiones en los patrones, indican que existen diferencias altamente significativas entre los tratamientos, habiéndose obtenido un coeficiente de variación de 5,06 \%. La prueba de comparación de las medias de Tukey de las áreas de avance en los patrones de los tratamientos de la metodología preventiva se presenta en la Tabla 4.

\section{Conclusiones}

Los productos de origen químico: Acibenzolar-S-metil, mananos oligosacáridos y fosetil aluminio son los mejores en la prevención Lasiodiplodia theobromae en plantas de vid. Mientras que los productos como ácido fosforoso, fosfito de potasio y sulfato de cobre pentahidratado tienen una eficacia limitada en la prevención de la enfermedad. Por otra parte, los productos de origen biológicos no fueron eficaces en la prevención a la de defensa de las plantas.

\section{Literatura citada}

Abdollahzadeh, J.; Mohammadi-Goltapeh E.; Zare, R. and Phillips A. 2010. Phylogeny and morphology of four new species of Lasiodiplodia from Iran. Persoonia 25:1-10.

Agrios G. N. 1996. Fitopatología. Ed Limusa. 2a ed. Mexico. $838 \mathrm{p}$.

Bamett, H. and Hunter, B. 1996. Illustrated general of imperfect fungi. The American Phytopathological Society. U.S.A. 218 p.

Costa, J.; Resende, M. and Ribeiro Junior, P. 2010. Induction of resistance in cacao seedling against Moniliophthora perniciosa by a phosphorilated mannan oligosaccharide based product. Trop. Plant Pathol, 35(5): 285-294.

Crous, P. and Palm, M. 1999. Reassessment of the anamorph genera Botryodiplodia, Dothiorella and Fusicoccum. Sydowia, 52:167-175.

Guest, D. 1984. Modification of defense responses in tobacco and capsicum following treatment with fosetyl-Al (aluminium tris (o- ethylphosphonate). Physiological Plant Pathology, 25: 125-134.

Guest, D. 1986. Evidence from light microscopy of living tissue that fosetyl-al modifies the defense response in tobacco seedlings following inoculations by Phytophthora nicotianae var. nicotianae. Physiological and Molecular Plant Pathology, 29: 251-261.

Heath, M. 2000. Hypersensitive response-related death. Plant Molecular Biology, 44:321-334.

Kedma, M.; Pinto, S. \& Cordeiro do Nascimiento L. 2012. Efficiency of resistance elicitors in the management of grapevine downy mildew Plasmopara viticola: epidemiological, biochemical and economic aspect. Brazil. Eur J Plant Pathol, 134: 745-754.

MINAGRI [Ministerio de agricultura y riego]. 2017. Estadística de producción agrícola. Disponible en: http://frenteweb.minagri.gob.pe/sisca/?mod=salida.

Mugnai, L.; Graniti, A. and Surico, G. 1999. Esca (black measles) and Brown Word-streaking: two old and elusive disease of grapevines. Plant Diseases, 83(5): 404-416.

Pearson, R. 2011. Plagas y enfermedades de la vid. Ediciones Mundi prensa. Madrid. $11 \mathrm{p}$.

Poscoe, I. and Cottral, E. 2000. Development in grapevine trunk diseases research in Australia. Phytopathologia Mediterránea, 39: 68-75.

Renault, A.; Deloire, A. and Bierne, J. (1996) Pathogenesisrelated proteins in grapevines induced by salicylic acid and Botrytis cinerea. Francia Vitis, 35(1): 49-52.

Reynier, A. 1989. Manual de Viticultura. Sexta Edición. 
Editorial Mundi-Prensa. Madrid, España. 382p.

Ryals, J.; Neuenschwander, U.; Willits, M.; Molina, A.; Steiner, H. and Hunt, M. 1996. Systemic acquired resistance. The Plant Cell, 8:1009-1819.

Santiago, S.; Gabriel, D.; Moctezuma, V.; Ernestina \& Cibrián, D. 2015. Identificación molecular del complejo Botryosphaeria sp. asociado a cancros y secamiento de yemas en Eucalyptus sp. Revista mexicana de ciencias forestales, 6(32): 93-106.

SAS Institute. 2004. SAS/STAT. User's Guide. Version 9. Vol. 1-5.SAS Publishing. Cary. N.C. USA.

Schneider, M.; Schweizer, P.; Meuwly, P. and Metraux, J. 1996. Systemic acquired resistance in plants. 300 p.

Sutton, B. 1980. The Coelomycetes. Commonwealth Mycological Institute, kew, Surrey, England 696 p.

Urbez-Torres J.; Leavitt, G.; Guerrero, J.; Guevara, J. and Gubler, W. 2008. Identification and pathogenicity of Lasiodiplodia theobromae and Diplodia seriata, the agents causal of bot canker disease of grapevines in Mexico. Plant diseases, 92: 519-529.

Van Loon, L. \& Pieterse, C. 2006. Significance of inducible defense-related proteins in infected plants. Annu. Rev. Phytopathol, 44: 135-162.

Van Niekerk, J.; Crous, P.; Groenewald, J.; Fourie, P. and Halleen, F. 2004. DNA phylogeny, morphology and pathogenicity of Botryosphaeria species on grapevines. Mycologia, 96: 781-798. 